\title{
Severe Thrombocytopenia Associated With Pembrolizumab in Patients With Non-small Cell Lung Cancer (NSCLC): A Case Report and Literature Review
}

\author{
ATSUTO MOURI, KYOICHI KAIRA, AYAKO SHIONO, YU MIURA and HIROSHI KAGAMU \\ Department of Respiratory Medicine, Comprehensive Cancer Center, \\ International Medical Center, Saitama University Hospital, Saitama, Japan
}

\begin{abstract}
Background/Aim: Thrombocytopenia, one of many immune-related adverse events (irAEs), is a rare entity about which little is known on its treatment, outcomes, and patient demographics. Herein we present a case of severe thrombocytopenia after administration of pembrolizumab as an anti-programmed death-1 (PD-1) antibody. Case Report: A 66-year-old man with advanced non-small cell lung cancer (NSCLC) received pembrolizumab; 21 days later, his platelet count was progressively decreased and he experienced severe thrombocytopenia (grade 4; platelet count $0.4 \times 10^{9} / l$ ). With oral steroids $1 \mathrm{mg} / \mathrm{kg} /$ day, the platelet count improved sufficiently; thus, a definite diagnosis of severe irAE-related thrombocytopenia was performed. Conclusion: Several reports have described the management and occurrence of severe thrombocytopenia after immune checkpoint inhibitor administration in patients with different neoplasms. Physicians should be alert to the potential of rare irAEs, such as severe thrombocytopenia.
\end{abstract}

Immune-related adverse events (irAEs) commonly occur during the administration of immune checkpoint inhibitors (ICI) such as anti-programmed death-1 (PD-1)/programmed death ligand-1 (PD-L1) antibodies. Myelosuppression is a common toxicity associated with cytotoxic chemotherapy, but it is relatively rare in patients with advanced non-small cell lung cancer (NSCLC) who received molecular targeting

This article is freely accessible online.

Correspondence to: Kyoichi Kaira, MD, Ph.D, Department of Respiratory Medicine, Comprehensive Cancer Center, International Medical Center, Saitama University Hospital, 1397-1 Yamane, Hidaka-City, Saitama 350-1298, Japan. Tel: +81 429844111, Fax: +81429844741, e-mail: kkaira1970@yahoo.co.jp

Key Words: Thrombocytopenia, PD-1, pembrolizumab, irAE, lung cancer. therapy or ICI. Several researchers have reported the potential of severe thrombocytopenia secondary to anti-PD1/PD-L1 antibodies in cases of NSCLC or malignant melanoma (1-7). As a first palliative therapy for the immunerelated toxicity of severe thrombocytopenia, corticosteroids are chosen to avoid immunological reactions in the bone marrow; if not effective, immunosuppressive agents or immunoglobulin are sequentially added to increase the platelet count (1-8). Because of the limited number of case series, only a few observations have been made on the appropriate management of ICI-related myelosuppression. Herein we present a case of severe thrombocytopenia related to anti-PD-1 antibody therapy and review the clinical features and therapeutic management in previous case series.

\section{Case Report}

A 66-year-old man was referred to our hospital with complaints of general fatigue and an abnormal chest shadow. The patient was a smoker with a disease history of pulmonary emphysema, gastric ulcer, and aneurysm. Diagnostic bronchoscopy confirmed an adenocarcinoma of cT3N3M1c. A physical examination was unremarkable and there were no driver mutations with high PD-L1 expression (tumor proportional score $=90 \%$ ). Because his disease expansion yielded stage IV with superior vena cava syndrome, he was treated with palliative radiotherapy in June 2019. After completion of palliative radiotherapy, pembrolizumab alone as an anti-PD-1 antibody was intravenously initiated in July 2019. On day 21 after initiation of pembrolizumab, his platelet count was decreased and he experienced severe thrombocytopenia (grade 4; platelet count, $0.3 \times 10^{9} / 1$ ). To confirm the diagnosis, we conducted a bone marrow puncture and exploratory investigation regarding infection, drug toxicity, collagen disease, and hematological disorders. Although a laboratory investigation revealed elevated platelet-associated immunoglobulin G (154 EU), any reason except for thrombocytopenia due to pembrolizumab was not 


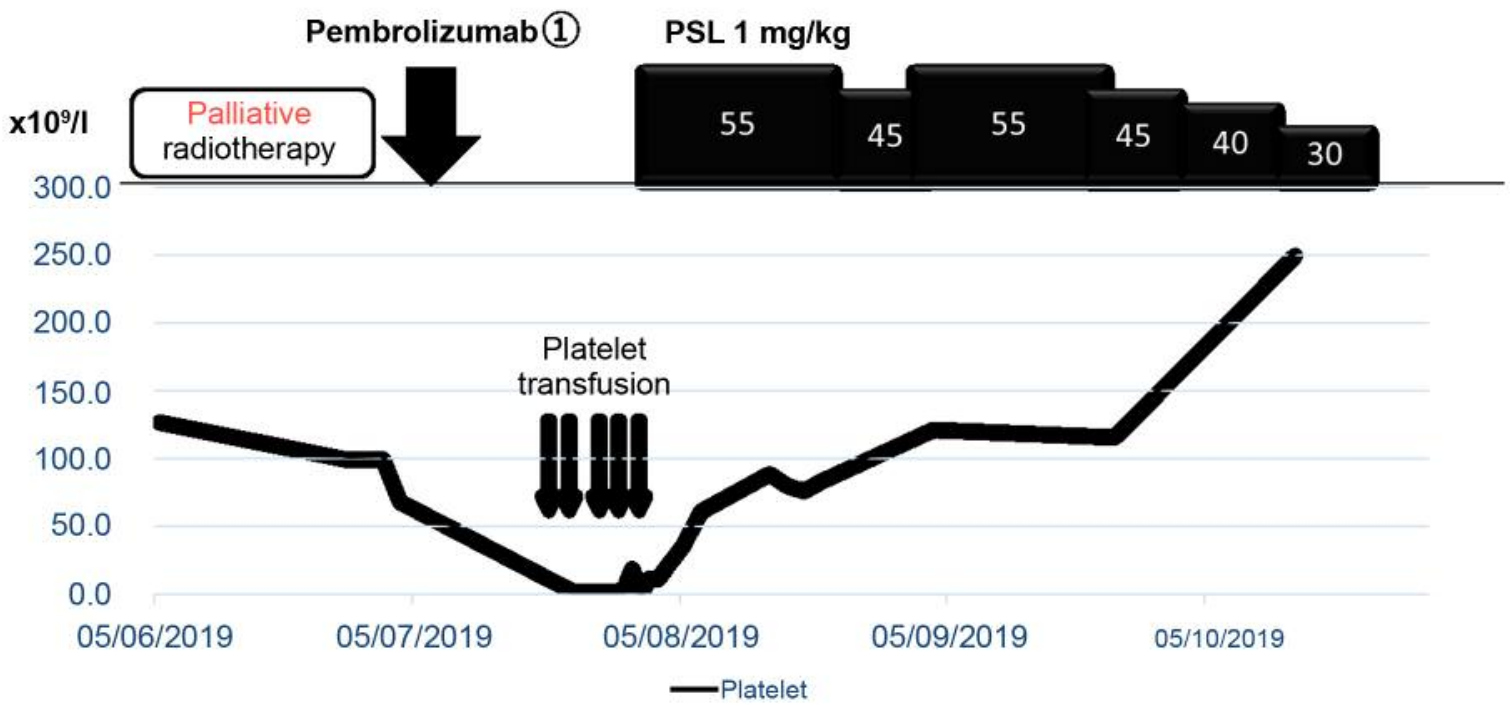

Figure 1. Clinical course from initiation of pembrolizumab to improvement of platelet count.

observed. Therefore, the pembrolizumab was immediately stopped. Despite repeated platelet transfusions, his platelet level did not increase; therefore, he was treated with oral steroids $1 \mathrm{mg} / \mathrm{kg} /$ day. His clinical course improved gradually to a sufficient platelet count and there was a marked reduction in the primary tumor (Figure 1). Once the prednisolone was tapered, new brain metastases appeared. Based on these reports, the rapid reduction in platelet count was considered due to the anti-PD-1 antibodies.

\section{Discussion}

This is an extremely rare case of severe thrombocytopenia associated with pembrolizumab use. Several reports have described the management and occurrence of severe thrombocytopenia after ICI administration in patients with different neoplasms (1-8). Table I shows the clinical features of patients with severe thrombocytopenia related to anti-PD1/PD-L1 antibodies. Aside from the current case, three cases have been identified as severe thrombocytopenia associated with anti-PD-1 antibody in patients with advanced NSCLC (13 ). Corticosteroid therapy was described as effective in previously reported cases of thrombocytopenia associated with irAEs, but there are still unknown data about the therapeutic significance of further immunosuppressive drugs or intravenous immunoglobulin (1-8). Among the nine patients who experienced severe thrombocytopenia as an irAE, seven exhibited improved myelosuppression, while the other two died. Given that severe thrombocytopenia as an irAE can become a dismal situation, early and appropriate treatment should be performed (1-8). Since the relationship between ICI efficacy and thrombocytopenia was unknown in five out of nine patients, it remains unclear whether thrombocytopenia as an irAE could predict ICI efficacy (1-8). In NSCLC, however, two out of four patients with NSCLC demonstrated a partial response to ICIs (1-3). Some patients required an oral thrombopoietin receptor agonist to supplement the effects of a systemic steroid and immunoglobulin $(2,6)$. Moreover, little is known on the detailed mechanism by which PD-1 blockade treats thrombocytopenia. Almost all previously reported patients [8/9 (89\%)] were male, but it remains unknown why severe thrombocytopenia as an irAE occurs primarily in males. Hematological disorders, viral or bacterial infections, collagen diseases, productive diseases of thrombosis, exhaustive diseases of the platelets, drug-induced diseases and unknown such as idiopathic thrombocytopenic purpura have been clarified as any diseases related to thrombocytopenia.

Regarding management, in patients with severe thrombocytopenia regardless of any disease or reason, a platelet transfusion should be considered to avoid the occurrence of intracranial hemorrhage. When thrombocytopenia persists for several weeks, steroid or intravenous IgG may be necessary. The management by platelet transfusion is a main issue in patients with severe thrombocytopenia secondary to cytotoxic chemotherapy, whereas, systemic steroid and immunoglobulin administration is identified as a reasonable choice in those due to immunotherapy (9-11).

Physicians should be alert to the potential of rare irAEs such as severe thrombocytopenia as described herein. An immediate administration of corticosteroids is necessary to successfully achieve irAE improvement after initiation of ICIs. 
Table I. Clinical features of patients with severe thrombocytopenia related to anti-PD-1/PD-L1 antibodies.

\begin{tabular}{|c|c|c|c|c|c|c|c|c|}
\hline Ref. & $\begin{array}{l}\text { Age } \\
\text { Gender }\end{array}$ & $\begin{array}{l}\text { Cancer } \\
\text { types }\end{array}$ & ICI & $\begin{array}{c}\text { PLT } \\
\left(\times 10^{9} / 1\right)\end{array}$ & $\begin{array}{l}\text { Treatment to } \\
\text { thrombocytopenia }\end{array}$ & $\begin{array}{l}\text { Efficacy } \\
\text { to ICI }\end{array}$ & $\begin{array}{l}\text { Duration from } \\
\text { ICI start to } \\
\text { thrombocytopenia } \\
\text { (Grade 4) }\end{array}$ & $\begin{array}{c}\text { Outcome of } \\
\text { thrombocytopenia }\end{array}$ \\
\hline (1) & $\begin{array}{l}62 \\
M\end{array}$ & NSCLC & Nivolumab & 16 & PSL & Unknown & Unknown & Improvement \\
\hline (2) & $\begin{array}{l}65 \\
M\end{array}$ & NSCLC & $\begin{array}{l}\text { Pembrolizumab } \\
\text { (combined with } \\
\text { CBDCA+PTX) }\end{array}$ & 0 & $\begin{array}{c}\text { Dexamethasone } \\
\text { (equivalent to PSL } \\
1 \mathrm{mg} / \mathrm{kg} / \text { day), IVIg, } \\
\text { Eltrombopag }\end{array}$ & PR & 157 days & Improvement \\
\hline (3) & $\begin{array}{l}37 \\
M\end{array}$ & NSCLC & $\begin{array}{c}\text { Durvalmab } \rightarrow \\
(\mathrm{CBDCA}+\mathrm{PEM} \rightarrow \\
\mathrm{PTX}+\mathrm{BEV})\end{array}$ & Unknown & $\begin{array}{l}\text { PSL } 1 \mathrm{mg} / \mathrm{kg} / \text { day, } \\
\text { IVIg } 25 \mathrm{~g} \times 4 \text { days }\end{array}$ & Unknown & 206 days & Died \\
\hline (4) & $\begin{array}{l}54 \\
M\end{array}$ & Melanoma & Ipilimumab & 3 & $\begin{array}{c}\mathrm{mPSL} 120 \mathrm{mg} / \text { days } \\
\times 4 \text { days } \\
\rightarrow \text { PSL } 1 \mathrm{mg} / \mathrm{kg}\end{array}$ & PD & 21 days & Improvement \\
\hline (5) & $\begin{array}{l}57 \\
\mathrm{M}\end{array}$ & Melanoma & Ipilimumab & 4 & $\begin{array}{l}\text { PSL } 1 \mathrm{mg} / \mathrm{kg} / \text { day, } \\
\text { IVIg } 1 \mathrm{~g} / \mathrm{kg}\end{array}$ & Progression & 37 days & Improvement \\
\hline (6) & $\begin{array}{l}79 \\
\mathrm{~F}\end{array}$ & Melanoma & Nivolumab & 2 & $\begin{array}{c}\mathrm{mPSL} 250 \mathrm{mg} / \text { day } \rightarrow \\
\text { PSL } 0.7 \mathrm{mg} / \mathrm{kg} / \text { day, } \\
\text { IVIg, Thrombopoietin } \\
\text { derivative (romiplostim) }\end{array}$ & Unknown & 28 days & Improvement \\
\hline (7) & $\begin{array}{l}34 \\
M\end{array}$ & Melanoma & Pembrolizumab & 1 & $\begin{array}{c}\mathrm{mPSL} 3 \text { days } \rightarrow \\
\text { PSL } 1 \mathrm{mg} / \mathrm{kg} / \text { day, } \\
\text { IVIg } 2 \mathrm{~g} / \mathrm{kg} \times 2 \text { days }\end{array}$ & Unknown & 21 days & Improvement \\
\hline (8) & $\begin{array}{l}77 \\
\mathrm{M}\end{array}$ & Merker & Avelumab & 5 & $\begin{array}{c}\mathrm{mPSL} 1 \mathrm{mg} / \mathrm{kg} / \mathrm{day}, \\
\text { Vitamin B12, } \\
\text { IVIg } 0.3 \mathrm{mg} / \mathrm{kg}, 3 \text { days }\end{array}$ & Unknown & 56 days & Died \\
\hline $\begin{array}{l}\text { Current } \\
\text { case }\end{array}$ & $\begin{array}{l}66 \\
M\end{array}$ & NSCLC & Pembrolizumab & 3 & PSL $1 \mathrm{mg} / \mathrm{kg} /$ day & PR & 21 days & Improvement \\
\hline
\end{tabular}

Ref, Reference; ICI, immune checkpoint inhibitor; PLT, minimal platelet counts at thrombocytopenia ( $\left.\times 10^{9} / 1\right)$; NSCLC, non-small cell lung cancer; PR, partial response; PD, progressive disease; PSL, prednisolone; mPSL, methyl prednisolone; IVIg, immunoglobulin; CBDCA, carboplatin; PEM, pemetrexed; PTX, paclitaxel; BEV, bevacizumab.

\section{Conflicts of Interest}

$\mathrm{AM}, \mathrm{KK}$, and $\mathrm{HK}$ received research grants and a speaker honorarium from Ono Pharmaceutical Company and Bristol-Myers Company. All other Authors declare no conflicts of interest.

\section{Authors' Contributions}

AM and KK: Conception and preparation of the manuscript. AM, AS and YM: Management of the patient. KK: Statistical analysis and patient's data collection. AM, KK and HK: Revising the manuscript. All Authors contributed and agreed with the content of the manuscript.

\section{Acknowledgements}

This research received no specific grant from any funding agency in the public, commercial, or not-for-profit sectors.

\section{References}

1 Jotatsu T, Oda K, Yamaguchi Y, Noguchi S, Kawanami T, Kido $\mathrm{T}$, Satoh $\mathrm{M}$ and Yatera K: Immune-mediated thrombocytopenia and hypothyroidism in a lung cancer patient treated with nivolumab. Immunotherapy 10: 85-91, 2018. PMID: 29260625. DOI: $10.2217 / \mathrm{imt}-2017-0100$

2 Song $\mathrm{P}$ and Zhang L: Eltrombopag treatment for severe refractory thrombocytopenia caused by pembrolizumab. Eur J Cancer 121: 4-6, 2019. PMID: 31563730. DOI: 10.1016/j.ejca

3 Leroy L, Lafarge X, Blouin L, Bijou F, Durrieu F, Olivier E and Le Moulec S: A fatal allo- and immune-mediated thrombocytopenia with a PD-L1 inhibitor. Ann Oncol 29: 514-515, 2018. PMID: 29088313. DOI: $10.1093 /$ annonc/mdx693

4 Kopecký J, Trojanová P, Kubeček O and Kopecký O: Treatment possibilities of ipilimumab-induced thrombocytopenia--case study and literature review. Jpn J Clin Oncol 45: 381-384, 2015. PMID: 25583422. DOI: 10.1093/jjco/hyu222 
5 Ahmad S, Lewis $\mathrm{M}$, Corrie $\mathrm{P}$ and Iddawela $\mathrm{M}$ : Ipilimumabinduced thrombocytopenia in a patient with metastatic melanoma. J Oncol Pharm Pract 18: 287-292, 2012. PMID: 21807763. DOI: $10.1177 / 1078155211411001$

6 Kanameishi S, Otsuka A, Nonomura Y, Fujisawa A, Endo Y and Kabashima K: Idiopathic thrombocytopenic purpura induced by nivolumab in a metastatic melanoma patient with elevated PD1 expression on B cells. Ann Oncol 27: 546-547, 2016. PMID: 26602778. DOI: 10.1093/annonc/mdv580

7 Le Roy A, Kempf E, Ackermann F, Routier E, Robert C, Turpin A, Marabelle A, Mateus C, Michot JM and Lambotte O: Two cases of immune thrombocytopenia associated with pembrolizumab. Eur J Cancer 54: 172-174, 2016. PMID: 26687374. DOI: 10.1016/j.ejca.2015.10.073

8 Kratzsch D, Simon JC, Pönitzsch I and Ziemer M: Lethal thrombocytopenia in a patient treated with avelumab for metastatic Merkel cell carcinoma. J Dtsch Dermatol Ges 17: 73 75, 2019. PMID: 30549433. DOI: 10.1111/ddg.13722

9 Shao YY and Hong RL: Fatal thrombocytopenia after oxaliplatin-based chemotherapy. Anticancer Res 28: 3115-3117, 2008. PMID: 19031966.
10 Bjelic-Radisic V, Stöger H, Winter R, Beham-Schmid C and Petru E: Long-term control of bone marrow carcinosis and severe thrombocytopenia with standard-dose chemotherapy in a breast cancer patient: a case report. Anticancer Res 26: 16271630, 2006. PMID: 16619583.

11 Sato N, Beppu T, Kinoshita K, Yuki H, Suyama K, Yuruki H, Motohara T, Chiyonaga S and Akahoshi S: Partial splenic embolization for lenvatinib therapy-associated thrombocytopenia among patients with hepatocellular carcinoma. Anticancer Res 39: 6895-6901, 2019. PMID: 31810959. DOI: 10.21873/anticanres. 13909

Received December 31, 2019

Revised January 18, 2020

Accepted January 20, 2020 